\title{
GAMBARAN TINGKAT PENGETAHUAN PERAWAT DALAM MENGIDENTIFIKASI KESELAMATAN PASIEN DI IGD RSUD MGR GABRIEL MANEK, SVD ATAMBUA NUSA TENGGARA TIMUR
}

\author{
Crisogna de Araujo ${ }^{1)}$ \\ Christina Anugrahini ${ }^{2}$ \\ Djulianus Tes Mau ${ }^{3)}$ \\ 1) 2) 3) : Program Studi Keperawatan Universitas Timor Kampus Atambua Jln. Wehor Kabuna \\ Haliwen Atambua, Nusa Tenggara Timur. Post: 85711. Phone: 082146075759
}

\begin{abstract}
ABSTRAK
Latar Belakang: Perawat dalam bekerja didasari oleh pengetahuan termasuk tentang keselamatan pasien.Tujuan penelitian : mendeskripsikan Pengetahuan Perawat Dalam Mengidentifikasi Keselamatan Pasien di IGD RSUD Mgr. Gabriel Manek, SVD Atambua. Desain penelitian menggunakan pendekatan kuantitatif dengan metode analisis deskriptif. Sampel penelitian ini adalah responden yang memenuhi kriteria inklusi di IGD rumah sakit Mgr. Gabriel Manek, SVD Atambua sebanyak 20 sampel. Alat pengumpulan data berupa kuesioner. Selanjutnya dilakukan analisa Univariat. Hasil penelitian tentang gambaran tingkat pengetahuan perawat dalam hal tahu kategori cukup 35\%, baik $40 \%$ dan kurang25\%, memahami kategori baik $25 \%$, cukup $50 \%$ dan kurang 25\%, mengaplikasi kategori baik 95\%, cukup 5\%. Kesimpulan : Gambaran Tingkat Pengetahuan Perawat IGD RSUD Mgr. Gabriel Manek, SVD Atambua tentang pasien safety adalah baik sebesar $60 \%$
\end{abstract}

Kata kunci :Tingkat pengetahuan, Identifikasi keselamatan pasien, perawat.

\section{DESCRIPTION OF NURSE'S LEVEL OF KNOWLEDGE IN IDENTIFYING PATIENT SAFETY IN EMERGENCY ROOM MGR GABRIEL MANEK, SVD ATAMBUA EAST NUSA TENGGARA}

\author{
Crisogna de Araujo ${ }^{1)}$ \\ Christina Anugrahini ${ }^{2)}$ \\ Djulianus Tes Mau ${ }^{3)}$
}

1) 2) 3) : Nursing Program at University of Timor Atambua Campus, Jl. Wehor Kabuna Haliwen Atambua, East Nusa Tenggara. Post: 85711, Phone: 082146075759

\begin{abstract}
Background : Nurses in work are based on knowledge including patient safety. The purpose of the study : describe the knowledge of nurses in identifying patient safety at the emergency room at the hospital in Mgr. Gabriel Manek, SVD Atambua.The research design uses a quantitative approach with descriptive analysis methods. The sample of this study was respondents who met the inclusion criteria in the emergency room at the Mgr hospital. Gabriel Manek, SVD Atambua, 20 samples. Data collection tool in the form of a questionnaire. Furthermore, Univariate analysis was carried out . Research result about the description of the level of knowledge of nurses in terms of knowing enough categories of $35 \%$, both $40 \%$ and less $25 \%$, understanding the good category $25 \%$, enough $50 \%$ and less $25 \%$, applying the good category $95 \%$, enough 5\% . Conclusion : An Overview of the Level of Knowledge of the Nurse of the IGD of the Hospital of Mgr Gabriel Manek, SVD Atambuaabout patient safety is good at $60 \%$
\end{abstract}

Keywords: Level of knowledge, Identification of patient safety, nurses. 


\section{PENDAHULUAN}

Didalam era digitalisasi seperti sekarang ini dimana perkembangan ilmu pengetahuan dan teknologi serta pertumbuhan ekonomi berkembang pesat, kebutuhan akan layanan kesehatan di rumah sakit juga terus berubah. Untuk itu perawat sebagai salah satu komponen utama pemberi layanan kesehatan kepada pasien memiliki peran penting sebagai ujung tombak pelayanan di rumah sakit, sebab perawat mempunyai waktu kontak dengan pasien lebih sering dibandingkan dengan tenaga kesehatan lainnya (Bantu et all, 2010). Agar dapat memberikan pelayanan yang profesional, perawat harus bertindak dengan didasari oleh ilmu pengetahuan termasuk pengetahuan tentang patient safety terutama di Instalasi Gawat Darurat, sebab tuntutan pelayanan di Instalasi Gawat Darurat bersifat cepat dan tepat (Depkes RI, 2006 dalam Abrori, 2015), sehingga asuhan keperawatan yang diberikan berkualitas dan bermanfaat yang berdampak pada baik buruknya mutu pelayanan di rumah sakit (Bantu et all, 2010), didukung dengan pengetahuan perawat yang cukup.

Worldh Health Organization (WHO) pada tahun 2004 mengumpulkan angka angka penelitian rumah sakit diberbagai negara Amerika, Inggris, Denmark, dan Australia, ditemukan Kejadian Tidak Diharapkan (KTD) dengan rentang 3,2 16,6\%. IOM (2000 dalam Mercola, 2011) juga melaporkan adanya insiden keselamatan pasien dalam pelayanan rawat inap di rumah sakit, kejadian yang terjadi yaitu kecelakaan pasien sekitar 3-16\% yang terjadi di Amerika Serikat. Di negara Australia, menurut Quality in Australia Health Care Study (QAHC) dari 14.179 jumlah klien yang masuk di rumah sakit didapatkan 2.353 Kejadian Tidak Diharapkan (KTD). Pada tahun 1999 sampai dengan 2000 di UK (United Kingdom) dari 1.014 jumlah klien yang masuk di rumah sakit terdapat 119 Kejadian Tidak Diharapkan (KTD). Laporan insiden keselamatan pasien di
Indonesia berdasarkan propinsi, pada tahun 2007 ditemukan Propinsi DKI Jakarta menempati urutan tertinggi yaitu $37,9 \%$ diantara delapan propinsi lainnya (Jawa Tengah 15,9 \%, Yogyakarta 13,8 \%, Jawa Timur 11,7 \%, Sumatera Selatan 6,9 $\%$, Jawa Barat 2,8 \%, Bali1,4 \%, Aceh 1,0 $\%$, Sulawesi Selatan 0,7 \%). Bidang spesialisasi unit kerja ditemukan paling banyak pada unit penyakit dalam, bedah dan anak yaitu sebesar 56,7 \% dibandingkan unit kerja yang lain. Sedangkan untuk pelaporan jenis kejadian, Kejadian Nyaris Cedera (KNC) lebih banyak dilaporkan sebesar 47,6 \% dibandingkan Kejadian Tidak Diharapkan (KTD) sebesar 46,2 \% (Devi, 2016). Komite Keselamatan Pasien Rumah Sakit (KKP - RS) dalam laporan Insiden Keselamatan Pasien (IKP) di Indonesia jumlah laporan IKP setiap tahun meningkat, diantaranya tahun 2007 sebanyak 145 kasus, tahun 2008 sebanyak 61 kasus, tahun 2009 sebanyak 114 kasus, tahun 2010 sebanyak 103 kasus, dan periode Januari - April 2011 sebanyak 34 kasus. Laporan kasus insiden keselamatan oleh KKP - RS pada bulan Januari - April 2011, menemukan bahwa adanya pelaporan kasus Kejadian Tidak Diharapkan (KTD) $(14,41 \%)$ dan Kejadian Nyaris Cedera (KNC) $(18,53 \%)$ yang disebabkan karena proses atau prosedur klinik $(9,26 \%)$ medikasi $(9.26$ $\%)$ dan pasien jatuh $(5,15 \%)$ (Abrori, 2017), untuk daerah Nusa Tenggara Timur, khususnya kabupaten Belu, berdasarkan pada profil kesehatan NTT tahun 2015, belum ada pelaporan Insiden Keselamatan Pasien oleh KKP - RS yang alasannya belum diketahui secara pasti.

Selain faktor pengetahuan perawat, faktor lain dari perawat seperti kelelahan, kondisi lingkungan yang buruk atau kekurangan staf, juga dapat menjadi penyebab kesalahan dalam memberikan pengobatan. Rumah sakit merupakan pelayananan kesehatan dimana didalamnya terdapat banyak jenis obat, bermacam macam tes dan prosedur, berbagai jenis 
alat dengan teknologi serta berbagai tenaga profesi dan non profesi yang harus memberikan pelayanan kepada pasien selama 24 jam secara terus - menerus, keberagaman serta kerutinan tersebut jika tidak dikelola dengan baik akan mengakibatkan Kejadian Tidak Diharapkan (KTD) (Pasaribu, 2017). Faktor perilaku perawat juga berperan penting dalam pelaksanaan keselamatan pasien, seperti perilaku yang tidak aman, lupa, kurangnya perhatiann / motivasi, kecerobohan, tidak teliti dan kemampuan yang tidak memperdulikan dan menjaga keselamatan pasien, beresiko untuk terjadinya kesalahan dan akan mengakibatkan cedera pada pasien berupa Near Miss (kejadian nyaris cedera / KNC) atau Adversevent (kejadian tidak diharapkan / KTD) (Lambogia et all, 2010). Peraturan Menteri Kesehatan RI Nomor 1691/ MENKES / PER /VIII /2000 Tentang Keselamatan Pasien Rumah Sakit menetapkan Enam Sasaran Keselamatan Pasien yang salah satunya dimulai dari identifikasi pasien, kesalahan identifikasi pasien tersebut dapat terjadi hampir dibanyak aspek, yang dapat mengakibatkan dampak yang serius bagi pasien seperti medication errors, kesalahan pemberian obat, salah dalam transfusi darah, pemberian prosedur pengobatan pada orang yang salah, bahkan juga bisa menyebabkan penyerahan bayi pada keluarga yang salah (Pasaribu, 2017).

Profesionalitas tenaga kesehatan memiliki karakter yang harus terpelihara dan ditingkatkan untuk mempertahankan standar mutu yang tinggi. Karakter tersebut ditunjukan dari perilaku tenaga kesehatan dalam memberikan pelayanan kesehatan termasuk pelaksanaan program patien safety berdasarkan standar pelayanan kesehatan, mandiri, bertanggung jawab, dan bertanggung gugat, serta mengembangkan kemampuan sesuai dengan perkembangan ilmu pengetahuan dan teknologi. (Lalel, 2019) Upaya penerapan patient safety sangat tergantung dari pengetahuan perawat, apabila perawat menerapakan patient safety didasari oleh pengetahuan yang memadai maka perilaku patient safety oleh perawat tersebut akan bersifat langgeng (long lasting) (Darliana, 2016). Namun kerja keras perawat tidak dapat mencapai level optimal jika tidak didukung dengan sarana, prasarana, manajemen rumah sakit dan tenaga kesehatan lainnya (Adib, 2009 dalam Bawelle, 2013). Anugrahini (2000) juga dalam penelitiannya menemukan bahwa kinerja perawat sangat berhubungan erat dengan kemampuan perawat dalam menerapkan pedoman patient safety di rumah sakit. Dengan adanya pelatihan atau seminar mengenai pengetahuan keselamatan pasien diharapkan mampu meningkatkan pengetahuan perawat, sehingga perawat mampu melaksanakan asuhan keperawatan dengan baik pula dan kecelakaan pasien dapat dicegah sedini mungkin (Abrori, 2017).

Berdasarkan uraian diatas, penulis tertarik untuk mengambil penelitian dengan judul "Gambaran Tingkat Pengetahuan Perawat Dalam Mengidentifikasi Keselamatan Pasien di IGD RSUD Mgr. Gabriel Manek, SVD Atambua Nusa Tenggara Timur"

\section{METODOLOGI}

Penelitian ini merupakan penelitian deskriptif kuantitatif dengan cross sectional untuk mengekspresikan tingkat pengetahuan perawat dalam mengidentifikasi keselamatan pasien di IGD RSUD Mr. Gabriel Manek, SVD Atambua Nusa Tenggara Timur. Populasi dalam penelitian ini adalah semua perawat di ruang IGD RSUD Mgr. Gabriel Manek, SVD Atambua Nusa Tenggara Timur terhitung mulai bulan April sampai bulan Juni 2018 dengan jumlah 20 orang. Teknik total sampling telah disebarkan kuisioner kepada 20 responden yang memenuhi kriteria inklusi, yaitu: perawat yang bersedia menjadi responden yang bertugas di ruang IGD RSUD Mgr. Gabriel Manek, SVD Atambua Nusa Tenggara Timur; dan 
perawat IGD RSUD Mgr. Gabriel Manek, SVD Atambua Nusa Tenggara Timur. Sedangkan kriteria eksklusinya adalah: perawat yang ijin; perawat yang cuti; dan perawat yang sakit. Analisa data menggunakan analisa univariat untuk mendeskripsikan masing-masing variabel yang diteliti.

\section{HASIL DAN PEMBAHASAN}

a). Gambaran Lokasi Pengambilan Data

Lokasi pengambilan data di RSUD Mgr.Gabriel Manek, SVD Atambua yang berada di jalan Dr. Soetomo no 2. Rumah sakit Umum Daerah (RSUD) Atambua resmi menyandang nama Tokoh Agama Rohaniawan Katolik Mgr.Gabriel Manek, SVD, nama Uskup orang pertama di pulau Timor sejak diresmikan oleh Bupati Belu Joachim Lopez pada jumat 14 februari 2014 di Atambua, dipilih nama tokoh tersebut karena terinspirasi dengan sosok almarhum yang semasa hidup selalu melayani dengan penuh cinta kasih dan tulus.

RSUD Mgr.Gabriel Manek, SVD Atambua memiliki luas tanah $32.732,34 \mathrm{~m}^{2}$ dengan luas bangunan $8.887 \mathrm{~m}^{2}$ dengan visi dan misi yaitu, Visi : menjadi rumah sakit rujukan yang mampu memiliki pelayanan yang prima, Misi : memberikan pelayanan yang bermutu dan berorientasi pada kepuasan pelanggan melalui pembangunan SDM dan menyediakan peralatan terstandar, memberikan pendidikan kesehatan menyeluruh bagi karyawan maupun institusi pendidikan, serta menjadikan RSUD Mgr.Gabriel Manek, SVD Atambua sebagai layanan umum. RSUD Mgr.Gabriel Manek, SVD Atambua juga menerima rujukan dari berbagai puskesmas dan rumah sakit swasta di kabupaten Belu maupun dari rumah sakit dari kabupaten lain seperti RSPP Betun (Malaka) dan rumah sakit Kefamenanu TTU (Timor Tengah Utara) yang terdiri dari beberapa ruangan diantaranya yaitu : IGD (Instalasi Gawat Darurat), Poli, Apotik, Rontgen, Laboratorium, Fisioterapi, Gizi, Loundri, kamar mayat, UTD (Unit Transfusi Darah), Ruang Bedah Central (OK) dan ruang perawatan (Bangsal Wanita, VIP, Bangsal Anak, Laki 3, Ruang Mutiara, Ruang Bedah, Ruang ICU, Ruang Nifas, Ruang Perina, Ruang VK dan Ruang Laki 2).

Untuk Ruang IGD (Instalasi Gawat Darurat) RSUD Mgr.Gabriel Manek, SVD Atambua sistem pelayanan menerapkan alur pelayanan sejak klien masuk di IGD mulai dari Triage sampai klien dipindahkan ke ruangan atau rawat jalan. Sistem Triage tersebut memiliki tingkat kategori sebagai berikut :

1) $P 1$ (Merah) adalah suatu keadaan yang memerlukan pertolongan segera dan apabila hal tersebut tidak dilakukan akan berakibat pada kecacatan organ bahkan kematian.

2) P2 (Kuning) adalah suatu keadaan yang memerlukan pertolongan segera namun dapat menunggu beberapa waktu dan bila hal tersebut tidak dilakukan akan terjadi suatu kegawatan.

3) P3 (Hijau) adalah suatu keadaan yang tidak memerlukan pertolongan segera, klien akan dirawat di ruang rawat jalan.

4) P4 (Hitam) adalah suatu keadaan yang tidak memerlukan pertolongan segera (pasien meninggal) dan akan diraat diruang jenazah.

Jumlah tempat tidur (TT) diruang Triage sebayak 3 buah, ruang pendaftaran sekaligus administrasi klien yang akan dirawat berada pada ruang Triage, ruang P1 sebanyak 4 TT, P2 sebanyak 4 TT, P3 sebanyak 3 TT, selain itu juga terdapat 2 troleyemergency pada zone $\mathrm{P} 1,1$ troley pada zone P2 dan P3 juga dilengkapi alat monitor dan alat emergency lainnya. Alat - alat dan obat emergency ditempatkan dalam lemari emergency dan boxnya masing- masing. Ruangan perawat atau nurse station 1 unit, 1 kamar untuk ruang ganti dan istrirahat dokter jaga, 1 ruang kamar mandi untuk petugas dan 1 kamar mandi / wc untuk pasien. 


\section{b). Karakteristik Responden}

Karekteristik responden dalam penelitian ini meliputi umur, tingkat pendidikan, lama kerja, status pernikahan dan status kepegawaian pada perawat di ruang IGD (Instalasi Gawat Darurat) RSUD Mgr.Gabriel Manek, SVD Atambua .

\section{b. HASIL PENELITIAN}

Tabel 1

DistribusiResponden Berdasarkan Umur Di Ruang IGD RSUD Mgr.

Gabriel Manek, SVD Atambua

Atambua Februari - Maret 2019

\begin{tabular}{cccc}
\hline No & Umur & $\begin{array}{c}\text { Frekuensi } \\
(\mathrm{F})\end{array}$ & $\begin{array}{c}\text { Presentase } \\
(\%)\end{array}$ \\
\hline 1 & $25-35$ & 13 & 65 \\
2 & tahun & 6 & 30 \\
3 & $36-40$ & 1 & 5 \\
& tahun & & \\
& $41-55$ & & \\
& tahun & & 100 \\
\hline 16 & Total & 20 & \\
\hline
\end{tabular}

Sumber : Data primer, 2019

Berdasarkan Tabel 1 diatas menunjukan bahwa dari 20 responden yang diteliti sebagian besar kelompok umur responden umur 25 - 35 tahun yaitu 13 orang $(65 \%)$ dan umur 41 - 55 tahun yaitu 1 orang ( $5 \%)$.

Tabel 4.2

Distribusi Responden Menurut PendidikanDi Ruang IGD

RSUD Mgr.Gabriel Manek, SVD Atambua Bulan Februari - Maret 2019

\begin{tabular}{llll}
\hline No & $\begin{array}{l}\text { Tingkat } \\
\text { Pendidikan }\end{array}$ & $\begin{array}{l}\text { Frekuensi } \\
(\mathrm{F})\end{array}$ & $\begin{array}{l}\text { Presentase } \\
(\%)\end{array}$ \\
\hline 1 & S.Kep, Ns & 3 & 15 \\
2 & D3 Kep & 17 & 85
\end{tabular}

Sumber : Data primer, 2019
Tabel 2 diatas menunjukan bahwa tingkat pendidikan sebagian besar responden dalam pnelitian ini yang berpendidikan D3 Keperawatan sebanyak $17(85 \%)$ dan berpendidikan S.Kep,Ns sebanyak 3 orang ( $15 \%$ ).

Tabel 3

Distribusi Responden Menurut Masa KerjaDi Ruang IGD RSUD Mgr.Gabriel Manek, SVD Atambua Bulan Februari - Maret 2019

\begin{tabular}{llcc}
\hline No & Masa Kerja & $\begin{array}{l}\text { Frekuensi } \\
(\mathrm{F})\end{array}$ & $\begin{array}{l}\text { Presentase } \\
(\%)\end{array}$ \\
\hline 1 & $4-14$ tahun & 17 & 85 \\
2 & $15-25$ tahun & 2 & 10 \\
3 & $26-36$ tahun & 1 & 5 \\
\hline 4 & Total & 20 & 100 \\
\hline
\end{tabular}

Sumber : Data primer, 2019

Tabel 3 menunjukan bahwa masa kerja sebagian besar responden dalam penelitian ini selama 4 - 14 tahun yaitu 17 responden $(85 \%)$ dan masa kerja 26 - 36 tahunyaitu 1 responden ( $5 \%$ )

Tabel 4

Distribusi Responden Menurut Status PernikahanDi Ruang IGD

RSUD Mgr.Gabriel Manek, SVD

Atambua Bulan Februari - Maret 2019

\begin{tabular}{llll}
\hline No & $\begin{array}{l}\text { Status } \\
\text { Pernikahan }\end{array}$ & $\begin{array}{l}\text { Frekuensi } \\
(\mathrm{F})\end{array}$ & $\begin{array}{l}\text { Presentase } \\
(\%)\end{array}$ \\
\hline 1 & Menikah & 12 & 60 \\
2 & Belum Menikah & 8 & 40 \\
\hline 3 & Total & 20 & 100 \\
\hline \multicolumn{4}{c}{ Sumber : Data primer, 2019}
\end{tabular}

Tabel 4 menunjukan bahwa status pernikahan sebagian besar responden dalam penelitian ini adalah yang sudah menikah yaitu 12 orang (60\%) dan yang belum menikah yaitu 8 orang ( $40 \%$ ). 
Tabel 5

Distribusi Responden Menurut Status

KepegawaianDi Ruang IGD

RSUD Mgr.Gabriel Manek, SVD

Atambua Bulan Februari - Maret 2019

\begin{tabular}{llll}
\hline No & $\begin{array}{l}\text { Status } \\
\text { Kepegawaian }\end{array}$ & $\begin{array}{l}\text { Frekuensi } \\
(\mathrm{F})\end{array}$ & $\begin{array}{l}\text { Presentase } \\
(\%)\end{array}$ \\
\hline 1 & $\begin{array}{l}\text { ASN (Aparat } \\
\text { Sipil Negara) }\end{array}$ & 9 & 45 \\
& $\begin{array}{l}\text { Tenaga Kontrak } \\
2\end{array}$ & 11 & 55 \\
\hline 3 & Total & 20 & 100 \\
\hline
\end{tabular}

Sumber : Data primer, 2019

Tabel 4 menunjukan bahwa status kepegawaian sebagian besar responden dalam penelitian ini sebagai Tenaga Kontrak yaitu 11 orang (55\%) dan sebagai ASN (Aparat Sipil Negara) yaitu 9 orang $(45 \%)$.

\section{Tabel 6}

Distribusi Frekuensi Tingkat Pengetahuan Perawat Dalam Hal Tahu (know)

\begin{tabular}{llll}
\hline Variabel & Kategori & $\begin{array}{l}\text { Frekuensi } \\
(\mathrm{F})\end{array}$ & $\begin{array}{l}\text { Presentase } \\
(\%)\end{array}$ \\
\hline \multirow{4}{*}{ Tahu } & Baik & 8 & 40 \\
& Cukup & 7 & 35 \\
& Kurang & 5 & 25 \\
\hline & Total & 20 & 100 \\
\hline
\end{tabular}

Sumber : Data primer, 2019

Berdasarkan tabel 6, dari 20 responden yang diteliti diketahui bahwa tingkat pengetahuan responden tentang patien safety dalam hal tahu (know) dengan kategori cukup yaitu 7 responden $(35 \%)$ dan kategori baik yaitu 8 responden $(40 \%)$ sedangkan untuk kategori kurang pada tingkat pengetahuan ini yaitu 5 responden $(25 \%)$
Tabel 4.7

Distribusi Frekuensi Tingkat

Pengetahuan Perawat Dalam Hal memahami (Comprehension)

\begin{tabular}{llll}
\hline Variabel & Kategori & $\begin{array}{l}\text { Frekuensi } \\
(\mathrm{F})\end{array}$ & $\begin{array}{l}\text { Presentase } \\
(\%)\end{array}$ \\
\hline \multirow{3}{*}{ Memahami } & Baik & 5 & 25 \\
& Cukup & 10 & 50 \\
& Kurang & 5 & 25 \\
\hline & Total & 20 & 100 \\
\hline
\end{tabular}

Sumber : Data primer, 2019

Berdasarkan pada tabel 7 dari 20 responden yang diteliti diketahui bahwa tingkat pengetahuan responden tentang patien safety

Tabel 4.8

Distribusi Frekuensi Tingkat

Pengetahuan Perawat Dalam Hal mengaplikasi (Aplication)

\begin{tabular}{llll}
\hline Variabel & Kategori & $\begin{array}{l}\text { Frekuensi } \\
(\mathrm{F})\end{array}$ & $\begin{array}{l}\text { Presentase } \\
(\%)\end{array}$ \\
\hline \multirow{3}{*}{ Mengaplikasi } & Baik & 19 & 95 \\
& Cukup & 1 & 5 \\
& Kurang & 0 & 0 \\
\hline & Total & 20 & 100 \\
\hline
\end{tabular}

Sumber : Data primer, 2019

Berdasarkan pada tabel 8 dari 20 responden yang diteliti diketahui bahwa tingkat pengetahuan responden tentang patien safety dalam hal mengaplikasi (Aplication) dengan kategori baik yaitu 19 responden (95\%), sedangkan untuk kategori cukup yaitu 1 responden (5\%) dan kategori kurang tidak ada responden $(0 \%)$ 
Tabel 9

Distribusi Frekuensi Tingkat Pengetahuan Perawat Tentang Patient Safety

\begin{tabular}{lccc}
\hline Variabel & Kategori & $\begin{array}{c}\text { Frekuensi } \\
(\mathbf{F})\end{array}$ & $\begin{array}{c}\text { Presentase } \\
(\mathbf{\%})\end{array}$ \\
\hline Tingkat & Baik & 12 & 60 \\
Pengetahuan & Cukup & 7 & 35 \\
tahu, & Kurang & 1 & 5 \\
$\begin{array}{l}\text { memahami, } \\
\text { aplikasi. }\end{array}$ & & & \\
\hline & Total & 20 & 100 \\
\hline
\end{tabular}

Berdasarkan pada tabel 9 dari 20 responden diketahui bahwa tingkat pengetahuan perawat di ruang IGD (Instalasi Gawat Darurat) RSUD Mgr. Gabriel Manek, SVD Atambua tentang Patient Safety dengan kategori baik sebanyak 12 responden (60\%) sedangkan untuk kategori cukup sebanyak 7 responden (35\%) dang untuk kategori kurang sebanyak 1 responden (5\%).

\section{PEMBAHASAN}

Penelitian ini bertujuan untuk mengetahui gambaran tingkat pengetahuan perawat tentang patient safety di ruang IGD (Instalasi Gawat Darurat) RSUD Mgr.Gabriel Manek, SVD Atambua dalam hal tahu (Know) memahami (comprehention) dan mengaplikasi (aplication). Berikut ini adalah pembahasan setiap tingkat pengetahuan berdasarkan hasil penelitian.

\section{a. Tingkat Pengetahuan Perawat IGD} RSUD Mgr.Gabriel Manek, SVD Atambua Tentang Patient Safety Berdasarkan Karakteristik Umur

Hasil penelitian ini menunjukan bahwa dari 20 responden yang diteliti sebagian besar kelompok umur responden umur 25 - 35 tahun yaitu 13 orang $(65 \%)$ dan umur 41 - 55 tahun yaitu 1 orang ( $5 \%$ ).

Hasil penelitian ini sesuai dengan pendapat menurut Robbins (2006) dalam
Anugrahini (2010) mengemukakan bahwa usia 20 - 40 tahun merupakan tahap dewasa muda. Tahap dewasa muda merupakan puncak dari kondisi fisik dalam mengaplikasiakan ilmu pengetahuan dan keterampilan yang dimilikinya. Hal ini diperkuaat oleh Wijaya et all (2016) bahwa umur seseorang menentukan produktivitas kinerja yang lebih baik karena umur akan mempengaruhi kondisi fisik, mental, kemampuan kerja dan tanggung jawab seseorang.

Robbins dalam Anugrahini (2010) juga mengatakan bahwa semakin bertambah usia seseorang semakin meningkat pula kedewasaan tekhnisnya, demikian pula psikologis, menunjukan kematangan jiwa. Usia yang semakin meningkat akan meningkatkan pula kebijaksanaan kematangan seseorang dalam mengambil keputusan, berpikir rasional, mengendalikan emosi dan toleransi terhadap pandangan orang lain. Usia tersebut berkaitan erat dengan tigkat kedewasaan atau maturitas seseorang. Semakin tinggi usia semakin mampumenunjukan kematangan jiwa dan semakin dapat berpikir rasional, semakin bijaksana, mampu mengendalikan emosi dan semakin terbuka terhadap pandangan orang lain. Perkembangan ini memungkinkan adanya pemikiran yang terbaik dan penilaian yang tepat bagi perawat dalam menerapkan pedoman patient safety.

Menurut Notoatmodjo (2010) umur seseorang yang bertambah dapat membuat perubahan pada aspek fisik psikologis, dan kejiwaan. Dalam aspek psikologis taraf berpikir seseorang semakin matang dan dewasa.

Pratama (2017) mengemukakakan bahwa umur yang produktif dalam bekerja dan merupakan angkatan kerja ditunjukan oleh periode dewasa muda ( 20 - 40 tahun ) dan dewasa madia ( $40-65$ tahun ). Dua kategori (periode) ini memiliki perbedaan yang dapat diketahui berdasarkan perkembangan fisik, kognitif, dan psikososial. Hal ini didukung oleh 
Lombogiaet all (2016) yang mengatakan bahwa umur individu mempengaruhi kondisi, fisik, mental, kemampuan dan cenderung absensi, sebaliknya yang umurnya lebih tua kondisi fisiknya kurang tetapi bekerja ulet dan mempunyai tanggung jawab lebih besar.

Peneliti berpendapat bahwa sebagian besar perawat diruang IGD RSUD Mgr. Gabriel Manek, SVD Atambua berada pada usia yang produktif artinya pada usia ini memungkinkan perawat dalam masa kedewasaan dan kematangan dan dapat menerapkan semua kompetensi yang dimilikinya untuk menerapkan pedoman patient safety.

\section{b. Tingkat Pengetahuan Perawat IGD RSUD Mgr.Gabriel Manek, SVD Atambua Tentang Patient SafetyBerdasarkan Karakteristik Pendidikan}

Hasil penelitian ini ditemukan bahwa tingkat pendidikan sebagian besar perawat berpendidikan D3 Keperawatan sebanyak $17(85 \%)$ dan berpendidikan S.Kep,Ns sebanyak 3 orang (15\%).

Menurut Notoatmodjo (2010) semakin tinggi tingkat pengetahuan seseorang, maka akan semakin mudah untuk menerima informasi tentang onyek atau yang berakitan dengan pengetahuan. Pendidikan sangat erat kaitannya dengan pengetahuan, pendidikan merupakan salah satu kebutuhan dasar manusia yang sangat diperlukan untuk pengembangan diri. Semakin tinggi tingkat pendidikan seseorang, maka akan semakin mudah untuk menerima, serta mengembangkan pengetahuan dan teknologi.Hasil penelitian ini juga sesuai dengan pendapat Pratama (2017) mengemukakan bahwa pendidikan merupakan salah satu faktor yang dapat mempengaruhi persepsi. Hal ini karena masing - masing jenjang pendidikan memiliki perbedaan pengetahuan dan cara pandang.

Hal ini diperkuat oleh Lombogia et all (2016) yang mengatakan bahwa sebagai profesi, keperawatan dituntut untuk memiliki kemampuan intelektual, interpersonal dan kemampuan teknis dan moral. Hal ini bisa ditempuh dengan meningkatkan kualitas perawat melalui pendidikan lanjutan pada program pendidikan Ners (Nursalam, 2012). Wijaya et alljuga mengatakan bahwa pelayanan keperawatan yang berkualitas dan kompoten berbasis patient safety akan terwujud bila perawat memiliki latar belakang pendidikan S1 (baccalaureate) dan atau lebih. Upaya mencapai keperawatan profesional di Indonesia salah satunya adalah dengan mengkonversi lulusan Akademi Keperawatan (Diploma 3 dan 4) untuk melanjutkan S1. Hal ini diperkuat oleh Hughes dalam Anugrahini (2010) yang mengatakan bahwa tingkat pendidikan merupakan salah satu karakteristik individu yang dapat meningkatkan pengetahuan perawat untuk dapat menerapkan pedoman patient safety, sehingga dapat menurunkan angka kejadian tidak diharapakan (KTD).

Penelitian ini sesuai dengan penelitian Anugrahini (2010) yang mengatakan bahwa tingkat pendidikan yang cukup tinggi, keterampilan dan pengetahuan perawat juga akan bertambah.

Peneliti berpendapat bahwa sebagian besar perawat diruang IGD RSUD Mgr. Gabriel Manek, SVD Atambua berpendidikan D3 Keperawatan maka perlu ditingkatkan ke jenjang yang lebih tinggi, sebab latar belakang pendidikan mempengaruhi pengetahuantentang patient safety.

c. Tingkat Pengetahuan Perawat IGD RSUD Mgr.Gabriel Manek, SVD Atambua Tentang Patient Safety Menurut Masa Kerja

Hasil penelitian ini menunjukan bahwa masa kerja perawat paling lama yaitu pada tahun $4-14$ tahun sebesar (85 $\%)$

Menurut Pratama (2017) mengatakan bahwa masa kerja seseorang menunjukan pengalaman kerjanya 
diinstitusi tertentu. Individu memperoleh banyak informasi mengenai situasi dan kondisi lingkungan kerjanya dalam pengalamannya. Pengalaman seseorang dapat mempengaruhi persepsi seseorang terhadap suatu informasi tertentu, karena dari banyaknya pengalaman atau masa kerja yang sudah lama mereka lebih banyak mengetahui situasi dan kondisi yang terjadi, sehingga memungkinkan mereka menilai atau menginterpretasikan stimulus sesuai kenyataan. Hal ini didukung oleh pendapat Notoatmodjo (2010) yang mengemukakan bahwa pengalaman seseorang sangat mempengaruhi pengetahuan, semakin banyak pengalaman seseorang tentang suatu hal, maka akan semakin bertambah pula pengetahuan seseorang akan hal tersebut. Pengukuran pengetahuan dapat dilakukan dengan wawancara atau angket yang menyatakan tentang isi materi yang ingin diukur dari subjek penelitian atau responden. Hal ini didukung oleh pendapat Wijaya et all (2016) yang mengatakan bahwa variasi dalam pengalaman kerja mendorong perawat untuk bertukar pendapat baik ilmu maupun keterampilan antar sesama perawat, sehingga perawat yang memiliki pengalaman pengalaman lebih banyak dapat memberi masukan pada perawat yang masih baru, sebaliknya perawat yang masih baru dapat memberikan masukan kepada perawat yang sudah lama tentang perkembangan terkini ilmu keperawatan. Hal ini diperkuat oleh Ellis et alldalam Anugrahini (2010) yang mengatakan bahwa perawat harus mempunyai pengalaman kerja yang cukup sehingga dapat mengerti tentang kebutuhan klien yang spesifik.

Peneliti berpendapat bahwa masa kerja perawat $4-14$ tahun termasuk dalam kategori junior dan senior di IGD RSUD Mgr.Gabriel Manek, SVD Atambua sehingga bisa saling melengkapi dalam penerapan tentang patient safety.

\section{d. Tingkat Pengetahuan Perawat IGD RSUD Mgr.Gabriel Manek, SVD Atambua Tentang Patient SafetyMenurut Status Pernikahan}

Hasil penelitian ini menunjukan bahwa proporsi perawat yang menikah lebih banyak dibandingkan dengan perawat yang belum menikah dengan presentasi yang menikah $60 \%$ dan yang belum menikah $40 \%$.

Hal ini tidak sesuai dengan pendapat Robbins \& Judge dalam Anugrahini (2010) yang mengatakan bahwa status perkawinan seseorang berpengaruh terhadap perilaku seseorang dalam kehidupan organisasinya. Karyawan yang menikah lebih sedikit absensinya, mengalami pergantian yang lebih rendah dan lebih puas dengan hasil pekerjaan daripada teman sekerjanya yang belum menikah.

Hasil penelitian ini tidak berbeda dengan penelitian Supriatin dalam Anugrahini (2010) yang menemukan ada hubungan bermakna antara status perkawinan dengan perilaku caring perawat.

Peneliti berpendapat bahwa dalam penerapan patient safety tidak ada perbedaan antara status yang sudah menikah dan belum menikah di IGD RSUD Mgr.Gabriel Manek, SVD Atambua. Perawat menerapkan pedoman patient safety kepada pasien yang dirawat sesuai dengan standar operasional prosedur (SOP) yang sudah diterapkan dari rumah sakit dan dilakukan dengan budaya kerja yang ada dirumah sakit tersebut.

\section{e. Tingkat Pengetahuan Perawat IGD} RSUD Mgr.Gabriel Manek, SVD Atambua Tentang Patient Safety Dalam Hal Tahu (Know).

Berdasarkan hasil penelitian menunjukan bahwa dari 20 responden yang diteliti bahwa tingkat pengetahuan perawat IGD RSUD Mgr.Gabriel Manek, SVD Atambua tentang patient safety 
dalam hal tahu (know) dengan kategori baik yaitu 8 responden (40\%) dan kategori cukup yaitu 7 responden (35\%), sedangkan kategori kurang pada tingkat pengetahuan ini yaitu 5 responden (25\%).

Menurut Notoatmodjo (2011) tahu diartikan sebagai mengingat suatu materi yang telah dipelajari sebelumnya. Termasuk kedalam pengetahuan tingkat ini adalah mengingat kembali (recall) terhadap suatu yang spesifik dari seluruh bahan yang dipelajari atau rangsangan yang telah diterima, oleh sebab itu "tahu" ini merupakan tingkat pengetahuan yang paling rendah. Kata kerja untuk mengukur bahwa orang tahu tentang apa yang dipelajari antara lain : menyebutkan, menguraikan, mendefinisikan, dan menyatakan. Hal ini dierkuat dengan pendapat Wijaya et all bahwa perawat harus mengetahui manfaat dari konsep patient safety sehingga akan muncul pemahaman bahwa dalam patient safety, pasien bukan hanya aman dan selamat, tetapi juga terbebas dari injuri aksidental dimana perawatan rumah sakit menjadi penyebabnya, terutama dalam mengidentifikasi pasien dengan benar meruapkan pondasi utama mencegah terjadinya error. Memeriksa minimal 2 dari 3 informasi identitas pasien yaitu nama pasien, nomor rekam medis, dan tanggal lahir akan memastikan bahwa setiap pasien mendapat pengobatan dan perawatan yang benar dan sesuai.

Dengan demikian dari hasil penelitian ini, peneliti dapat menjelaskan bahwa perawat IGD RSUD Mgr.Gabriel Manek, SVD Atambua memiliki kemampuan yang baik dalam mengingat kembali (recall) memori atau materi tentang patient safety.

\section{f. Tingkat Pengetahuan Perawat IGD RSUD Mgr.Gabriel Manek, SVD Atambua Tentang Patient Safety Dalam Memahami (Comprehention)}

Hasil penelitian menunjukan bahwa pada tingkat ini dari 20 responden diketahui bahwa tingkat pengetahuan perawat IGD RSUD Mgr.Gabriel Manek, SVD Atambua tentang Patient Safety dalam hal memahami (Comprehention) dengan kategori cukup yaitu sebanyak 10 responden (50\%), sedangkan untuk kategori baik sebanyak 5 responden $(25 \%)$ dan untuk kategori kurang sebanyak 5 orang $(25 \%)$.

Menurut Notoatmodjo (2010), memahami dapat diartikan suatu kemampuan menjelaskan secara benar tentang objek yang diketahui, dan dapat menginterpretasikan materi tersebut secara benar. Orang yang telah paham terhadap objek atau materi harus dapat menjelaskan, menyebutkan contoh, menyimpulkan, meramalakan, dan sebagainya terhadap objek yang dipelajari.

Berdasarkan pada hasil penelitian ini, peneliti dapat menyimpulkan bahwa dari 20 pertanyaan terbuka dalam kuesioner penelitian ini, tingkat pemahaman perawat IGD RSUD Mgr.Gabriel Manek, SVD Atambua adalah cukup dalam memahami atau menginterpretasikan tentang Patient Safety.

\section{g. Tingkat Pengetahuan Perawat IGD} RSUD Mgr. Gabriel Manek, SVD Atambua
(Aplication)

Hasil penelitian menunjukan bahwa pada tingkat ini dari 20 responden diketahui bahwa tingkat pengetahuan perawat IGD RSUD Mgr.Gabriel Manek, SVD Atambua tentang Patient Safetydalam hal Mengaplikasi (Aplication) dengan kategori baik sebanyak 19 responden (95\%), sedangkan kategori cukup sebanyak 1 responden (5\%), dan kategori kurang tidak ada responden $(0 \%)$.

Menurut Notoatmodjo (2010), aplikasi diartikan sebagai kemampuan untuk menggunakan materi yang telah dipelajari pada situasi atau kondisi riil (sebenarnya). Aplikasi disini dapat diartikan aplikasi atau penggunaan hukum - hukum, rumus, metode dan prinsip. 
Dalam penelitian ini, terdapat perbedaan jawaban antara jawaban responden dengan kunci jawaban berdasarkan kuesioner yang diadop dalam prinsip pemberian obat, sebab di IGD RSUD Mgr. Gabriel Manek, SVD telah menerapkan 8 prinsip benar dalam pemberian obat.

Dengan demikian dari hasil penelitian ini, peneliti dapat menyimpulkan bahwa sebagian besar perawat IGD RSUD Mgr.Gabriel Manek, SVD Atambua telah menerapkan tentang Patient Safety dalam situasi atau kondisi nyata dalam menangani pasien. Namun demikian perlu memperhatikan desain kerja di rumah sakit sebab disain kerja sangat mempengaruhi perawat dalam menerapkan pedoman patient safety di rumah sakit (Anugrahini, 2000)

\section{h. Tingkat Pengetahuan Perawat IGD RSUD Mgr. Gabriel Manek, SVD Atambua Tentang Patient Safety}

Hasil penelitian menunjukkan 20 responden diketahui bahwa secara keseluruhan tingkat pengetahuan perawat IGD RSUD Mgr. Gabriel Manek, SVD Atambua dengan kategori baik sebanyak 12 responden (60\%), sedangkan untuk kategori cukup sebanyak 7 responden (35\%) dan untuk kategori kurang sebanyak 1 orang $(5 \%)$.

Pengetahuan merupakan hasil penginderaan manusia, atau hasil tahu seseorang terhadap suatu objek dari indera yang dimilikinya (Notoatmojo, 2012). Hal ini diperkuat oleh pendapat Wijaya et allbahwa upaya patient safety telah dipromosikan dan diperjuangkan selama ini oleh berbagai organisasi kesehatan dunia, terutama Joint Comission International untuk menjamin keselamatan setiap pasien. Perawat akan selalu memiliki peran yang penting secara terus menerus mempromosikan perawatan yang aman sebagai satu - satunya kunci keberhasilan terciptanya patient safety. Tingkat pengetahuan ini juga seharusnya diimbangi dengan motivasi dan kinerja perawat. Sebagaimana penelitian yang ditemukan oleh Lalel, et al (2019) bahwa motivasi kerja tersebut sangat mempengaruhi kinerja seorang perawat di rumah sakit.

Berdasarkan pada hasil penelitian tersebut, peneliti dapat menyimpulkan bahwa 20 pertanyaan terbuka di kuesioner, gambaran tingkat pengetahuan perawat IGD RSUD Mgr. Gabriel Manek, SVD Atambua adalah baik dalam mengetahui, memahami dan mengaplikasikan tentang Patient Safety saat menangani pasien.

\section{KETERBATASAN PENELITIAN}

Peneliti menyadari bahwa penelitian ini masih jauh dari sempurna dan memiliki banyak keterbatsan serta memerlukan perbaikan. Dalam penelitian ini ada beberapa keterbatasan yang dihadapi, diantaranya :

1. Pada saat melakukan penelitian dan analisa data peneliti banyak mengalami kendala karena peneliti baru pertama kali melakukan penelitian.

2. Penelitian ini menggunakan kuesioner dengan pertanyaan sebanyak 20 pertanyaan terbuka yang diadop dari milik Khoirul Aziz Abrori tentang pengetahuan perawat IGD dalam mengidentifikasi keselamatan pasien di RSUD Dr. Harjono dan RSU Aisyiyah Ponorogo yang telah diuji validitas dan reabilitasnya, sedangkan penelitian ini dilakukan di wilayah dan Rumah Sakit yang berbeda yang bisa saja disebabkan oleh faktor karakteristik responden, tingkat pengetahuan dan pemahaman dan pengalaman pelayanan kesehatan yang berbeda pula diantara antara setiap orang, sehingga dapat mempengaruhi hasil dari penelitian ini.

3. Ada pertanyaan tentang prisip pemberian obat terdapat perbedaan jawaban antara kuesioner yang diadop dengan jawaban beberapa responden, yang mana jawaban responden tersebut berdasarkan buku panduan Patien Safety yang sesuai dengan standar 
WHO, sehingga dapat berpengaruh pada hasil penelitian ini.

4. Responden kurang mengerti / memahami pertanyaan yang diajukan dalam kuesioner penelitian ini sehingga berpengaruh pada hasil penelitian ini.

\section{KESIMPULAN}

Berdasarkan hasil penelitian diatas tentang Gambaran Tingkat Pengetahuan Perawat Dalam Mengidentifikasi Keselamatan Pasien Di IGD RSUD Mgr Gabriel Manek, SVD Atambua Nusa Tenggara Timur dari 20 responden yang diteliti dapat disimpulkan sebagai berikut : a. Gambaran Tingkat Pengetahuan Perawat Dalam Mengidentifikasi Keselamatan Pasien Di IGD RSUD Mgr. Gabriel Manek, SVD Atambua Nusa Tenggara Timur dalam hal tahu (know) adalah baik $(40 \%)$

b. Gambaran Tingkat Pengetahuan Perawat Dalam Mengidentifikasi Keselamatan Pasien Di IGD RSUD Mgr. Gabriel Manek, SVD Atambua Nusa Tenggara Timur dalam hal memahami (Comprehention) adalah cukup (50\%)

c. Gambaran Tingkat Pengetahuan Perawat Dalam Mengidentifikasi Keselamatan Pasien Di IGD RSUD Mgr. Gabriel Manek, SVD Atambua Nusa Tenggara Timur dalam hal mengaplikasi (aplication) adalah baik (95\%)

d. Secara umum tingkat pengetahuan perawat IGD RSUD Mgr. Gabriel Manek, SVD Atambua Nusa Tenggara Timur tentang patient safety adalah baik (60\%). Disarankan kepada manajer Rumah Sakit agar melakukan pelatihan yang berkesinambungan agar perawat IGD dapat mengupdate ilmunya secara lanjut.

\section{KEPUSTAKAAN}

Abrori Aziz Khoirul, 2017. Gambaran Tingkat Pengetahuan Perawat IGD Dalam Mengidentifikasi Keselamatan Pasien Di RSUD Dr. HARJONO Dan RSU AISYIYAH
Ponorogo. Program Studi DIII Keperawatan Fakultas Ilmu Kesehatan Univesitas Muhammadiyah Ponorogo.

Anggraeni Dewi, 2014. Sistem Identifikasi Pasien Di Instalasi Rawat Inap Rumah Sakit. Program Studi Magister Manajemen Rumah Sakit Fakultas Kedokteran Universitas Brawijaya Malang, 2014.

Anugrahini, C. (2000). Hubungan Faktor Individu dan Organisasi dengan Kepatuhan Perawat Dalam Menerapkan Pedoman Patient Safety di RSAB Harapan Kita Jakarta. Perpustakaan UI. Retrieved from http://lib.ui.ac.id

Anugrahini, C., \& Sahar, J. (2000). Kepatuhan perawat menerapkan pedoman. Jurnal Keperawatan Indonesia. http://doi.org/10.7454/JKI.V13I3.244

Bantu Anggraini,2014. Hubungan

Pengetahuan Perawat Dengan Penerapan Indentify Patient Safety Correccly Di RSUD Ratatotok Buyet Kabupaten Minahasa Tenggara. Program Studi Ilmu Keperawatan Fakultas Kedokteran Universitas Sam Ratulangi, 2014.

Bawelle Cintya Sellya, 2013. Journal Hubungan Dan Sikap Perawat Dengan Pelaksanaan Keselamatan Pasien (Patient Safety) Di Ruang Rawat Inap RSUD Kendage Tahuna. Progran i Ilmu Keperawatan Fakultas Kedokteran Universitas Sam Ratulangi, EJournal Keperawatan (E- Kp), Manado.

$\begin{array}{crr}\text { Belinda Melur, } & \text { Pelaporan } & \text { Insiden } \\ \text { Keselamatan } & \text { Pasien. } & \text { Tim } \\ \text { Keselamatan Pasien } & \text { RSUD } & \text { Dr. } \\ \text { Saiful Anwar Malang. } & & \end{array}$


Darliana devi, 2016. Hubungan Pengetahuan Perawat Dengan Upaya Penerapan Patient Safety Di Ruang Rawat Inap Rumah Sakit Umum Daerah DR. Zainal Abidin Banda Aceh. Idea Nursing Journal ISSN :2087 - 2879 Vol. VIII No. I.

Hastono, S.,P. (2007). Analisis Data Kesehatan. Fakultas Kesehatan Masyarakat Universitas Indonesia. Diklat. Tidak dipublikasikan.

KARS 2011 (Kemenkes RI), Standar Akreditasi Rumah Sakit.

Kemenkes. 2011. Peraturan menteri kesehatan republik indonesia nomor 1619 / menkes / per / 2011 tentang keselamatan pasien rumah sakit.

KKP - RS, 2008, Pedoman Insiden Keselamatan Pasien (IKP) (Patient Safety Incident Report) (Edisi 2). Jakarta : KKP - RS.

Lalel, CP., Berek, PAL., \& Nahak, H. (2019). HUBUNGAN ANTARA MOTIVASI KERJA DENGAN RELATIONSHIP BETWEEN WORK MOTIVATION WITH NURSE PERFORMANCE IN GENERAL HOSPITAL OF Mgr . GABRIEL MANEK SVD ATAMBUA. Jurnal Sahabat Keperawatan, 01, 1-13. Retrieved from https://jurnal.unimor.ac.id/JSK

Lambogia Anjelita, 2010. Hubungan Perilaku Dengan Kemampuan Perawat Dalam Melaksanakan Keselamatan Pasien (Patient Safety) Di Ruang Akut Instalasi Gawat Darurat Rsup Prof. DR. R. D. Kandau Manado. Program studi ilmu keperawatan fakultas kedokteran. e-journal.
Muslifa, 2010, Modul Penanggulangan Gawat Darurat.

N. Dewi Kartika. 2011. Buku Ajar Dasar - Dasar Keperawatan Gawat Darurat, Jakarta : Salemba Medika.

Notoatmodjo s, 2007. Kesehatan Masyarakat Ilmu Dan Seni, Jakarta, PT. Rineka Cipta.

Nursalam (2003). Konsep \& Penerapan Metodologi Penelitian Ilmu Keperawatan Pedoman Skripsi, Tesis Dan Instrumen Penelitian. Jakarta: Salemba Medika.

Pasaribu, 2017. Gambaran Pelaksanaan Ketepatan Identifikasi Pasien Oleh Perawat Di Instalasi Rawat Inap Kelas III RSUD PASAR MINGGU. Manajemen Pelayanan Kesehatan Masyarakat Fakultas Kedokteran Dan Ilmu Kesehatan Universitas Islam Negeri Syarif Hidayatullah Jakarta.

Pratama adhi pratama, 2017. Hubungan Tingkat Pengetahuan Tentang Penerapan Patient Safety Dengan Persepsi Penerapan Patient Safety Oleh Perawat Di RSUD Dr. Soediran Mangoen Soemarso Wonogiri. Program Studi Keperawatan Departemen Keperawatan Fakultas Kedokteran Universitas Diponegoro.

Sulayuningsih Evie. Journal Analysis $O f$ Patient Safety Management In Committe For Quality Improvement And Patient Safety At Sumbawa Hospital. West Nusa Tenggara, Departemen Of Anatomy. Faculty Of Medicine, Universitas Maret.

Wasis, 2008. Pedoman Riset Praktis Untuk Profesi Perawat. Jakarta : Penerbit Buku Kedokteran EGC. 